\title{
Interactive comment on "A high space-time resolution dataset linking meteorological forcing and hydro-sedimentary response in a mesoscale Mediterranean catchment (Auzon) of the Ardèche region, France" by Guillaume Nord et al.
}

G. NORD

guillaume.nord@univ-grenoble-alpes.fr

Received and published: 17 November 2016

Dear reviewer, We thank you for your careful reading of the paper. Before replying point by point to your comments, I realize that a lot of your comments are related to data accessibility. So, I have a general question: were you able to download the bundled data? I mean the files "zip1_auzon.zip" and "zip2_auzon.zip" available from the link to the data repository included in the abstract of the paper (http://mistrals.sedoo.fr/MISTRALS/?editDatsld=1438). Access to the file "zip1_auzon.zip" is totally public (see the flag "Direct access to public data") and does 
not require any identification. Access to the file "zip2_auzon.zip" is subject to the HyMeX data policy. We created a special account to allow publishers and reviewers to download this file "zip2_auzon.zip". We had sent a "cover letter" to the publisher at the time of submission of the paper to explain the procedure to download all the data (in particular the username and password of the account that enable to download the file "zip2_auzon. Zip "). Have you received this explanatory note? This bundling service represented an important task. It was performed to ease the download tasks for the interested users (as described in Section: 5 Data availability) as it enables to avoid the download of each individual datasets (41 in total). Best regards.

Interactive comment on Earth Syst. Sci. Data Discuss., doi:10.5194/essd-2016-32, 2016. 
ESSDD

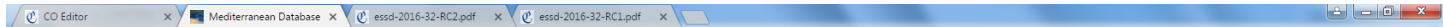
田公可 C) (i) mistrals,sedoo.fr/MISTRALSR ReditDatsid $=1438$

i:-i: Appications G Google

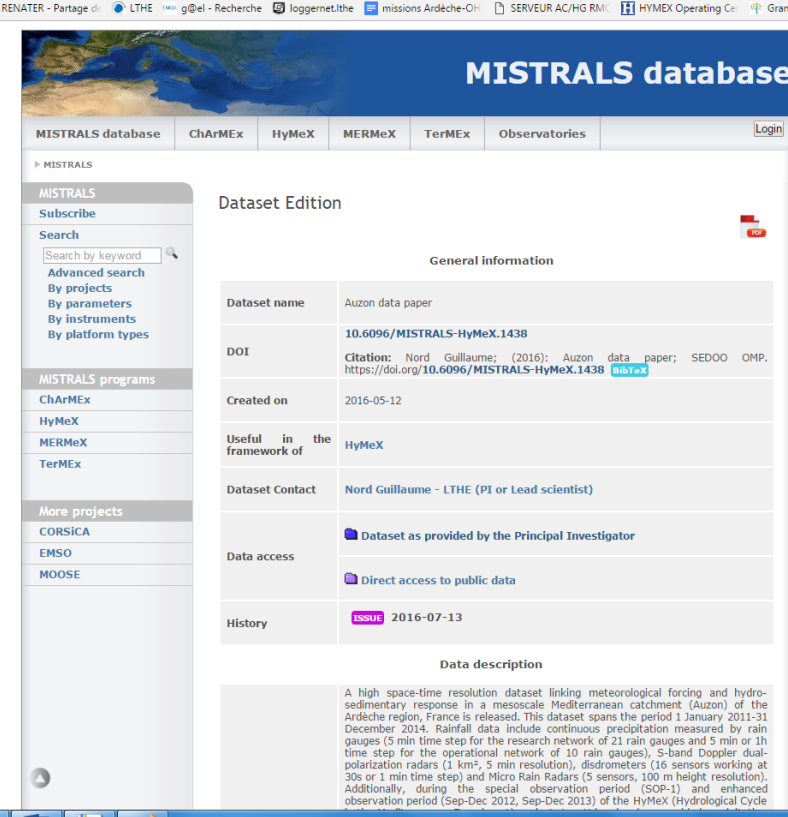

Interactive

comment

(4)

Fig. 1.

Discussion paper 